\title{
Announcements
}

\section{Psychologists for the Ethical Treatment of Animals Call for Papers}

Psychologists for the Ethical Treatment of Animals (PsyETA) is soliciting manuscripts for Volume 4 of Humane Innovations and Alternatives to Animal Experimentation: A Notebook. We invite short papers describing specific ways to minimize suffering and harm of laboratory animals. Areas of particular interest include husbandry and housing environments, experimental design, experimental procedure, and teaching methods.

Manuscripts are refereed by a distinguished board of editors who include scientists in biomedicine, toxicology and ethology, as well as psychology.

For more information and author guidelines, write to Emmanuel Bernstein, Glenwood Estates, Saranac Lake, NY 12983, or phone 518-891-4140.

(Volume 3 is now available and features over 25 brief articles [ 76 pp.]. The cost is $\$ 8$ for PsyETA members and $\$ 12$ for nonmembers. Send to PsyETA, P.O. Box 87, New Gloucester, ME 04260.)

\section{Second International Conference on Alzheimer's Disease and Related Disorders Toronto, Canada \\ July 15-20, 1990}

The Second International Conference on Alzheimer's Disease and Related Disorders, sponsored by the Institute for Basic Research in Developmental Disabilities, will be held at the Westin Harbour Castle, Toronto, Canada, July 15-20, 1990. Conference convenors are K. Iqbal, D. R. C. McLachlan, B. Winblad, and H. M. Wisniewski.

For further information and abstract forms, contact $\mathrm{Al}$ Snider, Conference Organizer, Institute for Basic Research, 1050 Forest Hill Road, Staten Island, NY 10314 (Telephone: (718)494-5299; Fax: (718)698-3803). 